\title{
EL ANGLICISMO EN ESPAÑOL: REVISIÓN CRÍTICA DEL ESTADO DE LA CUESTIÓN
}

\author{
María Jesús Rodríguez Medina
}

\begin{abstract}
The study of anglicisms in Spanish has always been controversial due to the purist attitude of some linguists who have regarded the presence of English words in the Spanish discourse only as a symbol of the Angloamerican international dominance after the Second World War. This paper reviews the main articles and books which have dealt with the English influence in Spanish since the end of the 1940s, when the first relevant study came out (Alfaro 1948), up to the latest publications on this field (Rodríguez González y Lillo 1997, Riquelme 1998). The need for further research in unexplored domains related to this phenomenon such as the morphosintactic calques is also emphasized.
\end{abstract}

\section{ANTECEDENTES}

El término anglicismo con valor de 'modismo de la lengua inglesa' se encuentra documentado en español desde $1784^{1}$ (Lorenzo 1996:13). Sin embargo, hay que trasladarse a 1948 para encontrar el primer tratado relevante dedicado en su totalidad al estudio del anglicismo en el mundo hispánico ${ }^{2}$ : "El anglicismo en el español contemporáneo", del abogado panameño R. Alfaro, aparecido primero en la revista Thesaurus en forma de artículo y posteriormente como introducción al Diccionario de anglicismos (1950), del mismo autor. Sin quitarle el mérito de haber sido uno de los primeros en analizar, de forma amplia y monográfica, los hechos lingüísticos derivados de la influencia del inglés en español, aunque no en la amplitud geográfica que cabría esperar ${ }^{3}$, la mayoría de los críticos ha coincidido en tachar a Alfaro de purista y radical en sus comentarios y observaciones (Teschner 1974:636).

\footnotetext{
${ }^{1}$ Casi un siglo después, en 1867, Cuervo recogía tan sólo siete anglicismos (Lorenzo 1971:70).

${ }^{2}$ Con la excepción de Spanish Don'ts (McHale 1939) y Anglicismos (Peyton y Carrasco 1944), citadas por Lorenzo (1971:71), obras sin repercusión en las investigaciones posteriores, hasta aquel momento sólo se había hecho referencia al fenómeno, de forma superficial y anecdótica, en estudios generales sobre el léxico del español de Hispanoamérica.

${ }^{3}$ El título, sin duda ambicioso, del artículo lleva a engaño, ya que Alfaro se centra en el español de América, principalmente, en el de Panamá.
} 
Por su parte, Pratt (1980:81) comenta que "la obra en sí constituye una muestra a la vez que una continuación de la escuela hispanoamericana fundada por A. Bello y R. Cuervo en el siglo XIX: normativista, prescriptiva y proscriptiva".

A pesar de las críticas que Alfaro ha recibido a propósito del carácter purista de sus comentarios, hay que reconocerle la aportación de la primera tipología publicada del anglicismo, que divide en once categorías (1948:115-118):

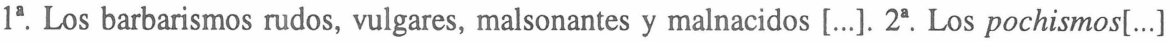
que son los vocablos y giros peculiares de los poches o pochos [...]. $3^{\mathrm{a}}$. Los anglicismos consistentes en [...] formar por paronimia voces alienígenas [...]. 4 ${ }^{\text {a }}$. Dicciones inglesas que tienen significado diferente y a veces opuesto [...]. $5^{\text {a }}$. [...] Palabras castizas[...] pero usadas con acepciones que no tienen en castellano [...]. $6^{\text {a }}$. Las dicciones que son de por sí castizas y se usan en su acepción corriente, pero que unidas a otras palabras producen una locución o giro anglicado [...]. $7^{\mathrm{a}}$. [...] Solecismos, o sean los giros, frases, locuciones o construcciones en que se agrupan voces castellanas conforme a la sintaxis inglesa [...]. $8^{\mathbf{a}}$. Los extranjerismos puros [...]. $9^{\mathrm{a}}$. [...] Neologismos producidos por la influencia inglesa [...]. 10 Los anglo-galicismos, o sean los barbarismos derivados de voces francesas puras que se ha apropiado el inglés[...]. 11 $1^{\mathrm{a}}$. Los pseudo-anglicismos, o sean ciertas dicciones a las cuales se da en castellano uso menos frecuente que el que tienen en inglés sus congéneres o parónimos [...].

En este primer intento de clasificación del anglicismo, se observan numerosas deficiencias y arbitrariedades, tal como señala, con acierto, Pratt (1980:93) en su análisis de esta tipología ${ }^{4}$. Sin embargo, hay que agradecer a Alfaro que, a pesar del tono exaltado con que redacta el artículo ${ }^{5}$, por el que ha recibido tantas críticas, adoptara también una actitud a favor de aceptar aquellos anglicismos que resulten enriquecedores para el idioma, lo que demuestra que, incluso para los tachados de puristas acérrimos, es imposible negar la utilidad del contacto de lenguas como fuente de ampliación del acervo léxico. A este propósito, escribe lo siguiente (Alfaro 1948:118-128):

[...] los anglicismos de lenguaje forman dos grupos fundamentales: primero, los superfluos, viciosos e injustificados, que son la gran mayoría; segundo, los extranjerismos y neologismos que pueden y deben adoptarse para enriquecer elidioma [...]. Hay que inclinarse [...] ante la necesidad de adoptar voces exóticas o neologismos útiles [...].

Algunos años después y también desde América, en concreto desde Estados Unidos, alza la voz contra los anglicismos Mallo (1954), con el artículo, de título elocuente, "La plaga de los anglicismos". Mallo no presenta una definición de este término, sino que, como se deduce del título de la publicación, se concentra en atacar, con dureza, lo que considera (1954:135) "una plaga que amenaza gravemente a la autenticidad de nuestro

\footnotetext{
${ }^{4}$ Compartimos de lleno los comentarios de Pratt, que sobra reproducir, pues, vistas a la luz de los estudios modernos, la ambigüedad de esta taxonomía y la ineficacia de los criterios seguidos son evidentes.

${ }^{5}$ Entre otros, recogemos estos ejemplos: "las voces extrañas al léxico y propias de gente zafia" (1948:115); "merecen un buen sepancuantos los numerosos individuos que por prurito de novedad [...] usan terminachos absurdos y construcciones enrevesadas [...]" (1948:119).
} 
idioma con el peligro de una corrupción deformante que destruiría uno de los valores fundamentales de la cultura hispánica"6. El artículo, donde impera el mismo tono purista y contundente que se aprecia en la cita (postura muy criticada por autores como Bowen (1954) y Bolinger $(1955)^{7}$, con los que Mallo mantuvo una sonada polémica), resulta interesante, como testimonio de la época, por la variedad de ejemplos de todo tipo que el autor describe con su apasionamiento habitual. No obstante, hay que señalar que incluso Mallo (1954:137) defiende el uso de palabras en inglés "cuando ello esté justificado o sea necesario porque no las haya o no puedan formarse en la auténtica lengua española".

En España, es Lorenzo, según palabras del propio autor (1995a:263), el primero en dedicar al anglicismo un artículo monográfico. En "El anglicismo en la España de hoy", publicado primero en Arbor en 1955 e incluido luego en el libro El español de hoy, lengua en ebullición (1966), se plantea la necesidad de prestar mayor atención a un fenómeno que Lorenzo (1971:70) considera ya "de transcedencia lingüística, social y nacional". Por vez primera, un lingüista se detiene a describir las manifestaciones, entonces incipientes, de la influencia inglesa y estadounidense en España ${ }^{8}$.

Aunque critica los desplazamientos morfosintácticos, las pérdidas de matices semánticos y los barbarismos ortográficos (1971:78-82) que se producen por la presión de la lengua inglesa, Lorenzo defiende, desde el comienzo del artículo hasta el final, el contacto del español con el inglés como vía de enriquecimiento lingüístico y rechaza las actitudes conservadoras ante el anglicismo (1971:70-85):

Queremos ceñirnos aquí al aspecto puramente lingüístico, en el cual -vaya esto por delanteno hemos podido ver los terribles peligros que algunos señalan [...]. Es posible dejar paso libre a cualquier expresión extranjera que venga a añadir un matiz nuevo a otra nuestra [...].

Sin duda, resultan admirables estas observaciones, si tenemos en cuenta la tendencia purista implacable que imperaba cuando se escribieron. La contribución de Lorenzo, en aquel momento, como precursor de esta línea de investigación en España e introductor de consideraciones novedosas como la descripción de los aspectos socioculturales, que también estaban cambiando por influencia de la cultura angloamericana, es innegable. No obstante, se ha criticado, con razón, que no presentara, en este artículo pionero, ningún tipo de definición del término anglicismo.

Aunque es cierto que estaba clara su postura con respecto a cómo determinar la utilidad o ineficacia de un anglicismo, según aporte o no matices nuevos (1971:74), Lorenzo tardó años en ofrecer una definición del fenómeno o una clasificación de las manifestaciones de

\footnotetext{
${ }^{6}$ Tan sólo una frase, lacónica y nada aclaratoria, le sirve para ubicar el fenómeno: "el impacto del inglés sobre el español engendra el anglicismo" (1954:135).

${ }^{7}$ Teschner (1974:646) reproduce algunos de los comentarios enfrentados de los tres polemistas.

${ }^{8}$ Lorenzo (1971:71) menciona a Casares, Laín Entralgo y Galiano, entre los intelectuales que, sin tratar el fenómeno en toda su amplitud, se habían hecho eco de éste en alguna conferencia o artículo. Nótese que manejamos la edición de 1971 de la citada obra.
} 
éste, tarea que, en aquel entonces, habría resultado muy útil para la homogeneización de los criterios seguidos por otros investigadores en publicaciones posteriores. A nuestro juicio, su definición más clara de anglicismo es la presentada ya en los años noventa (Lorenzo 1991:68):

Anglicismo es cualquier hecho cultural, principalmente idiomático, que procede de la esfera anglosajona y se instala, con mayor o menor resistencia y oportunidad, en la nuestra.

Uno de los primeros en ofrecer una delimitación, más que definición, del término es Stone (1957:142), cuyo estudio está centrado también en España:

He considerado como anglicismos palabras usadas en su forma inglesa o derivadas del inglés; palabras que pasaron de otros idiomas al inglés, y de éste, al español; o bien del inglés al español a través del francés; términos y vocablos creados por gentes de habla inglesa e introducidos en el español; palabras castizas usadas en un sentido inglés (préstamos semánticos o contaminaciones); y traducciones de tropos, complejos y modismos ingleses.

La visión que Stone expone del concepto de anglicismo es, como se observa en sus palabras, muy primitiva, pues incluye casos de índole diversa que poco tienen que ver entre sí. Esta delimitación, demasiado vaga, de los distintos fenómenos aporta poco, ya que no sigue una clasificación precisa de cada uno de ellos. De alguna manera, es necesario distinguir, por ejemplo, entre lo que Stone denomina "traducciones de tropos, complejos y modismos" de algo tan diferente como los "calcos semánticos", que no define en ningún momento. Por otro lado, Teschner (1974:667) se lamenta de la falta de rigor de la lista de anglicismos que incluye Stone, a la que no acompañan las consideraciones etimológicas, definiciones y referencias al uso que hubiesen conferido mayor validez a los datos.

Resultan también de interés los comentarios que Lapesa (1963:196-200) dedica a esta cuestión en el artículo "La lengua desde hace cuarenta años". Aunque muchos de los anglicismos citados por él ya están plenamente integrados en la lengua, constituyen, sin duda, un testimonio valioso para el estudio diacrónico del fenómeno en español. Lapesa (1963:196) se hace eco del "gran auge del anglicismo" que se vivía en nuestro país en los años sesenta. Además de comentar distintos tipos de anglicismos léxicos y semánticos, haciendo referencia, quizás por vez primera en la lingüística española, a los falsos aliados (1963:197), hoy denominados falsos amigos, este autor (1963:199) realiza observaciones, muy comedidas, de hechos muy poco tratados hasta aquel momento: la introducción indirecta de anglicismos en español a través del francés, calcos sintácticos como "la extensión anglicista del artículo indefinido" o "el empleo del gerundio como participio de presente en función adjetiva".

Por último, cabe destacar que, aunque Lapesa tampoco presenta ninguna definición del término anglicismo, llama la atención su uso irónico de dolarismo, con que se refiere a las palabras que llegan al español por influencia de Estados Unidos.

Tres años después de la aparición del artículo de Lapesa, en 1966, publica Madariaga su famoso “¿Vamos a Kahlahtahyood?”. A diferencia de Lapesa, Madariaga (1966:365) se 
muestra radicalmente en contra de lo que considera "una situación humillante de mera colonia del inglés" y denuncia (1966: 370), con apasionamiento, que seamos "mera colonia lingüística de Inglaterra aun cuando podríamos ser independientes". La actitud de Madariaga (1966:366) se aprecia, de forma clara, en afirmaciones como "no se ve por qué las tontilocas de Madrid se han ido a buscar al inglés una frase que traducen mal, pronuncian peor y es además inexacta" o "no daré mucho espacio a sandeces como romance por idilio".

Este ensayo, donde Madariaga repite mucho de lo que había comentado en "El español, colonia lingüística del inglés" (1962), se centra sobre todo en la traducción deficiente de los nombres propios extranjeros al español, por seguirse las pautas ortográficas inglesas, en detrimento de las propias de nuestra lengua (1966:368-373). Sin duda, si dejamos de lado el tono exaltado de la obra, las páginas que Madariaga dedica a los anglicismos resultan útiles incluso en la actualidad, ya que aborda algunos aspectos poco tenidos en cuenta por los traductores y lingüistas de hoy en día. No obstante, es evidente que algunas de las afirmaciones de este historiador, por tajantes y radicales, chocan al lector moderno, pues se alejan del enfoque sosegado que debe caracterizar cualquier tipo de trabajo científico.

Lapesa (1966) replica al autor de este artículo con otro en el que, con la ecuanimidad que se echa en falta en las palabras de Madariaga, defiende algunos de los usos que éste rechaza, propone soluciones y se muestra claramente a favor del contacto enriquecedor con otras lenguas (1966:379):

En resumen, las circunstancias reclaman que en el uso de nuestra lengua tengamos una actitud de razonable abertura frente al neologismo: importar lo imprescindible y lo conveniente, sin fruncir demasiado ante alguna fruslería de contrabando. Los sagaces casuistas de antaño sabían que en ciertas ocasiones es necesario lo superfluo.

Con posterioridad, ya en los años setenta, se mantiene el interés suscitado por la cuestión del anglicismo. Además de numerosas referencias al fenómeno en artículos y libros, existen varias publicaciones españolas destacables: "Calcos sintácticos del inglés" (1970), de Estrany; "Los anglicismos en el ámbito periodístico" (1971), de Marcos Pérez; el estudio diacrónico del fenómeno del anglicismo que lleva a cabo Fernández García (1972): "Los anglicismos en español desde 1890 a 1936"; y "El uso y abuso de anglicismos en la prensa española de hoy" (1978), de England y Caramés.

El artículo de Estrany, aunque breve, llama la atención por ser uno de los primeros dedicados en su totalidad a los anglicismos sintácticos. Del libro de Marcos Pérez nos interesan, sobre todo, los comentarios que realiza en torno a las causas de la aparición de los anglicismos en español y algunas referencias solapadas a los anglicismos sintácticos. Dado que centra su corpus en la prensa española, resulta de utilidad, como testimonio de la época, para los numerosos trabajos sobre la misma cuestión aparecidos en los últimos años. Fernández García, por su parte, contribuye con su tesis al mejor conocimiento de la historia de los anglicismos en España, pues presenta una lista con ejemplos extraídos de revistas y periódicos de la época estudiada, en los que comenzaron a emplearse palabras de origen inglés. 
England y Caramés continúan la línea de investigación de los anglicismos en la prensa española iniciada por Marcos Pérez. Además de reconocer la importancia científica de este fenómeno en España (1978:77), presentan más datos al respecto, acompañados de una propuesta metodológica, novedosa en aquel momento, que intenta mejorar la aportada por Smith (1975) para determinar el arraigo de los anglicismos en español. Smith (1975:9) distingue entre anglicismos crudos y asimilados (estos últimos no los considera extranjerismos por estar ya integrados por completo en la lengua receptora), que cataloga a partir de tres criterios (1975:9-12), traducidos por England y Caramés (1978:80-81) como cambio de función, la facilidad para derivar nuevas formas (derivational productivity) y cambio semántico observable. Con el fin de corregir las deficiencias de esta clasificación, England y Caramés (1978:81-86) proponen que se tengan en cuenta estos factores: la historia, la sociedad, la fonología, la ortografía y la morfología. La contribución más significativa de England y Caramés es, sin duda, la de encontrarse entre los primeros en dejar constancia de la falta de rigor de los criterios seguidos en aquellas fechas en España para la aceptación o no de ciertos anglicismos.

En los años setenta, comienza también a ser notable la publicación de obras en torno a los aspectos sociolingüísticos del anglicismo. No cabe duda de que investigadores prestigiosos del léxico del español de Hispanoamérica como López Morales, Huyke y Lope Blanch se convierten en pioneros a la hora de tratar el anglicismo a la luz de la sociolingüística moderna ${ }^{9}$, luego desarrollada en España (Gimeno y Gimeno 1991:743). No obstante, estos trabajos adolecen aún de falta de rigor en lo que a definición del término se refiere, ya que es un cometido que se sale de sus objetivos.

Lope Blanch (1977) lleva a cabo un estudio meticuloso de los anglicismos de la norma lingüística de México, pero no presenta ningún tipo de definición, tarea de la que sí se ocupan, aunque de forma poco precisa, los otros dos autores. Así, Huyke (1977:69) aporta la definión siguiente del término, que divide en dos grupos:

1. Palabra cuya forma-ya sea adaptada fonéticamente al español o en su forma originalproviene del inglés. 2. Significado que se le atribuye a una voz debidamente aceptada en el idioma español que proviene de una voz inglesa.

Salta a la vista el carácter impreciso de la definición, en la que se engloba toda clase de anglicismos. Aún es más amplia, como indican Gimeno y Gimeno (1991:743), la que ofreció López Morales, quien, en la obra Dialectología y sociolingüística (1979:103), señala que "serán considerados anglicismos todas las interferencias cuya lengua-fuente sea el inglés”. El propio lingüista (1987:103) decide posteriormente incluir también las palabras procedentes de otras lenguas que llegan al español a través del inglés.

\footnotetext{
${ }^{9}$ Se trata de trabajos que aplican la metodología del "Proyecto de estudio coordinado de la norma lingüística culta de las grandes ciudades del mundo hispánico" y siguen con fidelidad el cuestionario léxico que ocupa el tomo tercero del Cuestionario para el estudio coordinado de la norma lingüística culta del PILEI (Programa Interamericano de Lingüística y Enseñanza de Idiomas) (Gómez Capuz 1993:1.302).
} 


\section{SITUACIÓN ACTUAL}

Es indudable que el paso decisivo hacia el concepto moderno de anglicismo no se produce hasta 1980, fecha en que Pratt publica el libro El anglicismo en el español peninsular contemporáneo, donde se recogen los resultados de su tesis doctoral. Los especialistas coinciden en afirmar que esta obra de Pratt constituye el trabajo más innovador, riguroso y completo de todos los aparecidos hasta entonces, y, por tanto, su valía dentro de los estudios del anglicismo en español es incuestionable.

Pratt (1980:104) cita la que para él es la primera definición ${ }^{10}$ aceptable del término anglicismo, aunque consideramos que queda en entredicho su validez, pues, en ella, éste se limita sólo a aquellos casos aparecidos en la prensa, lo que impide su aplicación en las investigaciones centradas en otros campos:

An anglicism is considered to be a word which has originated in British or American English and which is used in the Spanish Press in a modified or unmodified form.

Después de realizar un examen crítico de las investigaciones anteriores, en el que Pratt pone de relieve la tendencia purista y la carencia de una metodología rigurosa de la mayoría de ellas, el autor (1980:115) propone esta definición:

Un anglicismo es un elemento lingǘístico, o grupo de los mismos, que se emplea en el castellano peninsular contemporáneo y que tiene como étimo inmediato un modelo inglés.

Es evidente que resulta más rigurosa que las anteriores, sobre todo por la consideración de étimo inmediato, que permite incluir también aquellas palabras que no son de origen inglés, pero que llegan al español a través de esta lengua. Aunque admirable por su intento de rigor y concisión, creemos que adolece de una limitación importante al restringir el campo de acción del anglicismo al español peninsular. Pratt basa su investigación en un corpus de anglicismos recogidos en el español de la Península, como el propio título del libro indica, pero esto no justifica que, a la hora de definir un fenómeno tan extendido, se excluya al resto de las comunidades de habla española, donde la incidencia de éste es, si cabe, aún mayor ${ }^{11}$.

En cuanto a su clasificación de anglicismos (1980:115-212), observamos que es la primera vez que se intenta abarcar, de forma exhaustiva, la totalidad de las manifestaciones de éstos, con la consabida distinción entre anglicismos patentes (toda forma identificable como inglesa, o bien totalmente sin cambiar, o bien adaptada, parcial o totalmente, a las pautas ortográficas del español contemporáneo) y no patentes (aquellos anglicismos que se reconocen como formas españolas).

Opinamos que todas las novedades que Pratt introdujo -como el análisis riguroso y exhaustivo del corpus, cuya contribución al avance en la búsqueda de una clasificación útil

\footnotetext{
${ }^{10}$ Se trata de la utilizada por Bookless en su tesis inédita de 1968.

${ }^{11}$ Piénsese en el español de Hispanoamérica o de Canarias.
} 
de los anglicismos es indudable, la distinción entre étimo último e inmediato y la importancia concedida a los factores extralingüísticos como criterios para la identificación de los anglicismos- representan un logro, desde el punto de vista filológico, para los estudios del fenómeno que nos ocupa.

No obstante, echamos en falta una atención mayor a los anglicismos sintácticos, a los que apenas dedica tres páginas, frente al amplio espacio reservado para el comentario del léxico y de la ortografía. Por otro lado, consideramos que la clasificación, aunque brillante por su claridad e innovación, se centra demasiado en los aspectos formales y no tiene en cuenta las funciones pragmáticas de los anglicismos, de importancia en actividades como la traducción. Es posible que Pratt no haya tratado estas cuestiones por no formar parte de su ámbito de estudio y por no hallarse, en esa época, tan en boga como en la actualidad. Aun así, creemos que esta obra debe considerarse el punto de partida de los estudios publicados en los últimos años en torno a este campo.

En los años ochenta, decae un tanto el interés científico por los anglicismos en español. Si excluimos el libro de Pratt, el primer trabajo de los ochenta digno de mención es el publicado por Klein-Andreu (1980), en el que se valoran algunas aportaciones anteriores desde la perspectiva de la sociolingüística. Aunque centrado en el español de los puertorriqueños de Nueva York, ámbito bastante alejado del español europeo, las consideraciones de Klein-Andreu con respecto a los anglicismos sintácticos y a la falta de precisión metodológica de las obras anteriores resultan válidas para cualquier investigación en este terreno. No obstante, esta autora no ofrece ningún tipo de definición o propuesta de clasificación.

De 1984 es el estudio que realiza Quilis de los anglicismos en el español de la norma lingüística culta de Madrid. Quilis, además de no especificar los criterios seguidos para considerar anglicismo un término, se limita a ordenar éstos según el número de informantes que los ha empleado, método útil para los interesados en los estudios cuantitativos, pero poco aplicable a otro tipo de investigaciones.

Con respecto a la contribución de Lorenzo, hay que aclarar que, como ya hemos explicado, a pesar de haber sido uno de los pioneros en detectar la presencia de anglicismos en español, tarda bastante en ofrecer una clasificación rigurosa de éstos, hecho que critica Pratt (1980:97). Aunque Lorenzo alega que, ya desde 1971, aparece una taxonomía suya en una enciclopedia, no la publica en un artículo científico, a propósito de los anglicismos detectados en la prensa española, hasta pasados dieciséis años (1987:77-79):

Anglicismos crudos. Son aquellas palabras o expresiones que mantienen en español la grafía inglesa [...]. Anglicismos en período de aclimatación. [...] Se han ido adaptando a las condiciones del español [...]. Anglicismos totalmente asimilados. [...] Han tomado carta de naturaleza en nuestra lengua hace siglos [...]. Calcos. Son adaptaciones correspondientes a conceptos no reconocidos o desconocidos por el adaptador [...]. Calcos semánticos. Voces españolas que por su semejanza formal con otras inglesas reciben de este idioma acepciones que no posesían [...]. Anglicismos de origen extraeuropeo. [...] El inglés ha sido vehículo transmisor de un sinfín de voces del Oriente [...]. Anglicismos de origen clásico. [...] El 
inglés ha creado gran número de neologismos a partir del griego y el latín [...]. Anglicismos tomados de otros países europeos. [No los define] Anglicismos sintácticos. [No los define]

Por su parte, Smith (1989) es uno de los primeros, junto con Pratt, en tratar los anglicismos desde el punto de vista descriptivo, sin proscribir su uso. De este modo, con un planteamiento abierto y flexible, Smith (1989:125-129) señala hasta siete tipos de anglicismós en español que, a su juicio, ni siquiera se deben considerar ya como tales: los que adquieren significados desconocidos en inglés o extensiones morfológicas, los de origen grecolatino, los calcos semánticos, las colocaciones léxicas y sintácticas basadas en un modelo inglés, los que ya se han integrado plenamente en la lengua, y los pseudoanglicismos o falsos anglicismos de origen francés.

Opinamos que estas obsérvaciones, aunque en parte discutibles ${ }^{12}$, suponen un paso adelante en lo que puede denominarse "la postura moderada en torno al anglicismo" (Medina López 1996:18), imperante en los años noventa y de la que Smith es uno de los precursores. A comienzos del decenio de 1990, según Gómez Capuz (1997:30), “ya se puede hablar con propiedad de una madurez del anglicismo en español".

El siguiente trabajo en el que aparece una tipología de los anglicismos se publica en 1990. En "Esbozo sobre el uso y abuso del anglicismo en la prensa española", Caballero y Rigal (1990:62) señalan que, en general, se aprecian cuatro modalidades distintas:

1. La palabra inglesa "tal cual" insertada en un texto en español [...]. 2. Términos traducidos literalmente [...]. 3. Palabras inglesas adaptadas a la fonética de nuestra lengua. 4. Términos formados con palabras procedentes del inglés pero que no tienen nada que ver con el original inglés.

Se trata de una tipología muy rudimentaria e imprecisa, en la que se describen las manifestaciones de los anglicismos sin aportar un término riguroso para cada caso. A nuestro juicio, el criterio fundamental del que debe partirse para una concepción más clara de éstos es el que proponen Gimeno y Gimeno (1991:747):

Nuestra hipótesis de trabajo consiste en diferenciar abiertamente anglicismo léxico y préstamo integrado [...]. En la medida que el préstamo integrado conlleva una integración lingüística y social del modelo cabe considerarlo ya como parte de la gramática social de la comunidad $[\ldots]$

El hecho de plantear esta dicotomía resulta de mucha utilidad para los estudios de orientación sociolingüística que examinan el uso real de los anglicismos por parte de los hablantes y su actitud hacia ellos.

\footnotetext{
${ }^{12}$ Desde nuestro punto de vista, una lexía es siempre un anglicismo si tiene un étimo inglés (último o inmediato), ya esté adaptada o no al español, ya que con el término anglicismo sólo hacemos referencia al origen etimológico de la palabra en cuestión. No obstante, compartimos los criterios de Smith si lo que se pretende es distinguir aquellos anglicismos que el hablante (no el especialista) ya no siente como tales o cuya filiación inglesa es indirecta, de aquellos cuyo uso responde sólo a lo que Smith denomina the mania for foreignness (1989:131).
} 
Gómez Capuz (1992:302-316) ofrece una clasificación tipológica de éstos anglicismos basada en criterios formales:

1.Anglicismo ortográfico. Consiste en la transliteración de un nombre propio -topónimo o antropónimo- de una lengua que no emplea el alfabeto latino [...] conforme a las reglas ortográficas y fonémicas del inglés [...]. 2. Anglicismo semántico. En el préstamo semántico, [...] el español sólo recibe prestada una nueva acepción para una palabra ya existente [...]. 3. Anglicismo léxico. [...] La lengua receptora recibe una lexía compleja [...] de otra lengua, si bien esa lexía puede pasar a la lengua receptora tal como es en la lengua original [...], traducida por morfemas de la lengua receptora [...] o bien combinando los dos procedimientos anteriores [...]. 4. Calco sintáctico. [no lo define]

En una publicación posterior, este autor (1995:510-511) añade otros tipos novedosos de anglicismos como los anglicismos bimembres mutilados (skin< skinhead, basket< basketball), los anglicismos incrustados en modismos españoles (dejar K. O., casarse de penalty, montar un show) y las acepciones metafóricas e irónicas (bikini 'bocadillo caliente de jamón y queso', bistec 'lengua', playback 'simulación').

De 1996 es el volumen en el que Lorenzo revisa y actualiza la cuestión del anglicismo. Aunque resultan de mucha utilidad los comentarios y observaciones que dedica a numerosos términos, esta obra vuelve a adolecer del mismo defecto por el que se ha criticado tanto su artículo de 1955: la ausencia de una clasificación y una definición rigurosas de éstos. Lorenzo los divide en préstamos y calcos, sin aportar ningún tipo de definición para los primeros, aunque sí reproduce la del DRAE en el caso de los calcos. No obstante, hay que destacar que el apartado dedicado a la influencia del inglés en la sintaxis, aunque no tan completo como cabría esperar, es uno de los más amplios que se pueden encontrar en los escasos tratados al respecto.

A nuestro entender, el artículo de Rodríguez González "Functions of Anglicisms in Contemporary Spanish" (1996) es la aportación reciente más valiosa para la definición y clasificación de los anglicismos. Rodríguez González, quien parte de una visión científica del concepto, sin prejuicios ni consideraciones salidas de tono, reconoce (1996:108) que, a pesar de la variedad de material publicado en torno a esta cuestión, "much of the research done on the subject is lexicographic in outlook [...], but the general treatment of them is fairly incomplete and methodologically insufficient". Este lingüista (1996:109) se basa en los componentes funcionales del sistema semántico de la lengua que señala Halliday: ideacional, interpersonal y textual.

Rodríguez González (1996:110) incluye en el componente ideacional aquellos anglicismos que, según la definición de Halliday, corresponden a "the expression of processes and other phenomena of the external world, including the world of the speaker's own consciousness". El segundo tipo, los expresivos o interpersonales (1996:111), "mark personal or social relations [...] and by virtue of their 'foreign' nature are apt to develop an 'expressive' meaning, i.e. a meaning that expresses feelings or attitudes on the part of the speaker: irony, contempt, snobbery or affectation (prestige)". El tercer componente, el textual, es quizás el que da más juego, ya que engloba (1996:116) "borrowed expressions that have a purely textual function together with borrowings that have ideational and 
interpersonal meanings". Dentro de la función textual, Rodríguez González (1996:116-124) señala algunas funciones específicas que desempeñan los anglicismos (simpfication, precision and clarity, avoidance of ambiguity, emphasis, variation of expression, text enrichment).

El autor aporta, a lo largo del ensayo, ejemplos variados, con los que demuestra, en cada caso, la validez de sus argumentos. Es innegable que este artículo representa un avance considerable en los estudios del anglicismo, ya que en él se demuestra, por vez primera, la necesidad de aplicar criterios basados en el uso y en la pragmática para aceptar términos que, aun desempeñando una función lingüística clara en un contexto determinado, tradicionalmente se han rechazado, por parecer superfluos, de forma categórica. Hasta ahora, la tendencia ha sido la de criticar el uso de aquellos anglicismos que cuentan con equivalentes en español, sin tener en cuenta los matices distintivos de toda índole que éstos aportan en determinados contextos, como se encarga de dejar claro este autor.

Consideramos que la descripción que Rodríguez González realiza de las funciones de los anglicismos en el discurso, justificadas con criterios lingüísticos y extralingüísticos, da pie a una concepción abierta del fenómeno, de mucha utilidad como guía para profesionales de la lengua como los traductores o los periodistas, que por fin pueden recurrir al uso real de cada anglicismo en cuestión, en el contexto específico de cada caso, para decidir si es aceptable o no. Rodríguez González tiene el mérito, además, de haber publicado en 1997, en colaboración con Lillo, el Nuevo diccionario de anglicismos, que supone una actualización de las recopilaciones anteriores (Alfaro 1950, 1964, 1970; Fernández García 1972, Lorenzo 1996). La valía de este diccionario reside en que constituye un punto de referencia fiable para los estudiosos de los anglicismos léxicos que deseen averiguar los que se emplean en la actualidad, pues como este lingüista explica, de la página trece a la dieciséis de la introducción, se trata de un diccionario "descriptivo y no normativo, [...] cuyas voces se han extraído de las fuentes más variadas [...] contrastadas con datos procedentes de la radio y la televisión y de consultas a informantes de diferentes edades y niveles culturales".

El manual sobre el anglicismo en español de Riquelme (1998) constituye también una aportación destacada en este campo, puesto que es muy probable que constituya la primera obra en torno al anglicismo de naturaleza, ante todo, didáctica y no exclusivamente científica o académica. Destacamos el concepto, introducido por Riquelme (1998:35), de palabras viajeras para englobar aquellos términos surgidos en España o en algún país hispanohablante que se han transferido al inglés y que luego se han retomado de esta lengua con el sentido adquirido en el ámbito anglosajón, de forma que, en español, se pierde o se altera el significado original de estas lexías: embargo, silo, rodeo, tornado. Este concepto no es del todo nuevo, ya que, según Gómez Capuz (1998:88), lingüistas franceses y alemanes detectaron este fenómeno en sus lenguas y, para referirse a él, acuñaron, respectivamente, los términos emprunts aller-retour y Rückenlehnungen, traducidos por Lorenzo (1995b:168) como palabras de ida y vuelta. A juicio de Gómez Capuz, sería más preciso emplear la denominación préstamos de ida y vuelta. 
En definitiva, concluimos que, desde el inicio del fenómeno, hace ya casi medio siglo, el anglicismo léxico -no así el sintáctico- ha recibido la atención que merece por los estudiosos del español. Dado que la influencia internacional del inglés es cada día mayor, auguramos que este interés por la cuestión del anglicismo, lejos de perderse, se mantendrá más vivo que nunca en los años venideros, tiempo en que la investigación en este campo promete ser-fructífera.

\section{OBRAS CITADAS}

R. J. Alfaro, "El anglicismo en el español contemporáneo”, Thesaurus 4 (1948) 102-128.

----- Diccionario de anglicismos (Madrid 1950).

D.Bolinger, "Prescriptive Statements and Mallo's Anglicims", Hispania 38 (1955) 76-78.

J. D. Bowen, "Letter to the Editor: English Loan Words in Spanish", Hispania 37 (1954) 329-331

J. Caballero y M. Rigal,"Esbozo sobre el uso y abuso del anglicismo en la prensa española", Anales del.Centro de Albacete 11 (1990) 53-67.

J. England y J. L. Caramés, "El uso y abuso de anglicismos en la prensa española de hoy", Arbor 100 (1978) 77-89.

M. Estrany, “Calcos sintácticos del inglés”, Filología Moderna 38 (1970) 199-203.

A. Fernández García, Anglicismos en el español 1890-1936 (Oviedo 1972).

F. Gimeno y M. V. Gimeno, "El estado de la cuestión sobre el anglicismo léxico", Actas del III Congreso Internacional del español de América (Valladolid 1991) 741-749.

J. Gómez Capuz, "Anglicismos en las noticias sobre la Guerra del Golfo Pérsico. Visión actual del problema e intento de clasificación”, Lingüística española actual 14 (1992) 301-320.

----- "Tendencias en el estudio de las diferentes etapas de la influencia angloamericana en español moderno (con especial atención al nivel léxico)", Actas del III Congreso Internacional de Historia de la Lengua Española (Salamanca 1993) 1.289-1.307.

----- "El efecto del anglicismo en el español hablado y coloquial de España y de Hispanoamérica: análisis contrastivo", Congreso de historia de la lengua española en América y España I (Valencia 1995) 507-511.

----- "La madurez del anglicismo en español actual: el ejemplo de la lengua juvenil", Actas del V Encuentro de la Asociación de Jóvenes Lingüistas (1997 Murcia) 29-39.

----- El préstamo lingüístico: conceptos, problemas y métodos (Valencia 1998).

I. Huyke Freiría, "Anglicismos en el vocabulario culto de San Juan: cuatro campos léxicos", Estudios sobre el español hablado en las principales ciudades de América (México 1977) 63-83. 
F. Klein-Andreu, "La cuestión del anglicismo: apriorismo y métodos", Boletín de la Academia puertorriqueña de la lengua española 8 (1980) 58-71.

J. Lope Blanch, “Anglicismos en la norma lingüística culta de México”, Estudio sobre el español hablado en las principales ciudades de América, (México 1977) 271-279.

H. López Morales, Dialectología y sociolingüística (San Juan 1979).

---- “Anglicismos en Puerto Rico: En busca de los índices de permeabilización del diasistema. Diseño de investigación", Dialectología y sociolingüística. Temas puertorriqueños (Madrid 1987) 101-106.

R. Lapesa, "La lengua desde hace cuarenta años", Revista de Occidente 8 (1963)193-208.

---- "Kahlahtayood, Madariaga ha puesto el dedo en la llaga", Revista de Occidente 36 (1966) 373-380.

E. Lorenzo, "El anglicismo en la España de hoy", El español de hoy, lengua en evolución (Madrid 1971) 70-93.

---- "Anglicismos en la prensa", Actas de la I Reunión de Academias de la Lengua Española sobre el Lenguaje y los Medios de Comunicación (Madrid 1987) 71-79.

---- “Anglicismos y traducciones”, Studia Patricae Shaw Oblata II (Oviedo 1991) 67-79.

----- "El anglicismo, problema hispánico". Boletín de Filología 35 (1995a) 261-274.

----- “Anglicismos”, La lengua española hoy (Madrid 1995b) 165-174.

----- Anglicismos hispánicos (Madrid 1996).

S. Madariaga, "El español, colonia lingüística del inglés", Cuadernos del Congreso por la libertad de la cultura 59 (1962) 45-49.

---- “¿Vamos a Kahlahtahyood?”, Revista de Occidente 36 (1966) 365-373.

J. Mallo, “La plaga de los anglicismos”, Hispania 37 (1954) 135-140.

P. J. Marcos Pérez, Los anglicismos en el ámbito periodístico: algunos de los problemas que plantean (Valladolid 1971).

J. Medina López, El anglicismo en el español actual (Madrid 1996).

C. Pratt, El anglicismo en el español peninsular contemporáneo, (Madrid 1980).

A. Quilis, "Anglicismos en el español de Madrid", Satura grammatica in honorem Francisco Rodríguez Adrados I, (Madrid 1984) 413-423.

J. Riquelme, Los angli(ci)smos: anglismos y anglicismos, huéspedes de la lengua (Alicante 1998).

F. Rodríguez González, "Functions of Anglicisms in Contemporary Spanish", Cahiers de lexicologie 68 (1996) 107-128. 
F. Rodríguez González y A. Lillo Buades, Nuevo diccionario de anglicismos (Madrid 1997).

C. Smith, “Anglicism or Not?”, Vida Hispánica 23 (1975) 9-13.

---- "The Anglicism: No Longer a Problem for Spanish", Actas del XIII Congreso de AEDEAN (Tarragona 1989) 119-136.

H. Stone, "Los anglicismos en España y su papel en la lengua oral", Revista de Filología Española 41 (1957) 141-160.

R. Teschner, "A Critical Annotated Bibliography of Anglicisms in Spanish", Hispania 57 (1974) 631-678. 